\title{
Xiaomi India's New Distribution Method in the Post-Pandemic Era
}

\author{
Wanyu Li* \\ Beihang University, Beijing 100062, China \\ *Corresponding author: Wanyu Li, liwanyu_viola@126.com
}

\begin{abstract}
In recent years, the Indian smartphone market has grown rapidly, and Xiaomi's expansion in this market has never stopped. However, Xiaomi India has and would face even more changes and challenges due to the impact of the COVID-19 pandemic. This paper focuses on how Xiaomi India can adhere to its ethical business practices in changes and developments that will improve its distribution layout.
\end{abstract}

Keywords: Post-pandemic era; Xiaomi India; Distribution method; Ethical business

Publication date: August 2021; Online publication: August 30, 2021

\section{Introduction}

The smartphone market in India has grown to become the second largest smartphone market in the world. The demand for smartphones in India is expected to grow in the future primarily because the smartphone penetration in India is still low compared to the worldwide average. COVID-19 has facilitated a steady development for the e-commerce. Such digital transformation cannot progress without smartphones or personal computers (PC) in which both of them have low penetration in India.

Beginning in April 2020, COVID-19 gradually spread in India with an outbreak in May 2021. Up to 410,000 new diagnoses were being confirmed daily. As a result of the pandemic, the whole supply chain in India such as manufacturing, retail, and logistic system have all been impacted in varying degrees.

Being the second largest smartphone market in the world, India is of great importance to Xiaomi. With a market share of up to $25 \%$, Xiaomi has occupied the first place in the Indian mobile phone market for thirteen consecutive quarters. Lifted by the outstanding results in India, Xiaomi's global mobile phone shipments had once reached third place in the world ranking. Xiaomi's revenue in India accounts for $20 \%$ of the company's total revenue. In the pandemic, Xiaomi India's strategy and implementation would be the cornerstone for its future market success in India.

\section{Xiaomi's development history in India}

Among the many overseas markets, Xiaomi took India as its top foreign market out of its global expansion strategy and entered the Indian market in July $2014^{[1]}$. Xiaomi, as a multinational company has undertaken series of localization strategy initiatives to fit into what works best to operate in India.

(1) In the initial stage of entering the Indian market, Xiaomi exported all mobile phone models to the Indian market for sale.

(2) Since 2014, Xiaomi India has shifted from a trade model to an OEM manufacturing model. 
(3) Responding to India's Modi government promotion of "Make in India" campaign, Xiaomi has taken the initiative to begin production localization in India. Xiaomi has commissioned Foxconn since 2015 to set up two factories and production lines in India to carry out the local assembly and production of mobile phones in India.

(4) With the expansion of its business in India, Xiaomi's team in India grew from scratch and eventually set up an Indian branch to overall steer Xiaomi's end-to-end business in India, including marketing, distribution management, and sale activities with area autonomy ownership. Headed by an Indian, Manu Jain, the company employs Indians to form the Xiaomi India team.

\section{Challenges for Xiaomi's development in India under the pandemic era}

Due to low labor cost, high import tariff, and a vast mobile phone market in India, coupled with large investments by head companies, the out-migration of Chinese factories to India has gradually taken shape in recent years. Except for a few components, most of the products in the mobile phone industry can be produced and sold in India. However, after the COVID-19 lockdown, the survival of small and mediumsized supply chain companies are in jeopardy as distribution channels and couriers are at a loss resulting from areas or cities in lockdown ordered by the local governments and due to the concern of the COVID19 infection. Not only the upstream of mobile phones, but also the downstream distributors and retailers were under great pressure.

At the beginning of 2020, the Indian political and business leaders generally believed that Trump would win the election. They expected to use the Indo-Pacific strategy to turn to the United States. Since April 2020, the Indian government has been introducing restrictive policies against Chinese companies in a number of product areas.

The Modi government is convinced that the global value and the industrial chains would be restructured after COVID-19 while maintaining a supporting attitude of India's market advantages. He believes that the United States and the European countries would massively invest in India.

In this political and economic context, Xiaomi's development in India will be restricted until the global pandemic is alleviated, and mobile phone manufacturing factories as well as the terminal sales in India will be on hold. Xiaomi's development in India may be forced to slow down and even abandon certain business chains in India.

\section{Xiaomi's adherence to ethical business in the post-pandemic era}

The pandemic subjects large multinational companies such as Xiaomi to new social responsibility standards

${ }^{[2]}$. Xiaomi, as a multinational company with strong ties to India, has chosen to actively shoulder the social responsibility to help India overcome the impact of COVID-19. Since April 2021, India has suffered from more than 300,000 reported new cases daily.

In April 2020, Xiaomi donated 100 million rupees across Indian state governments, government hospitals, and state police. Immediately after April 22, in response to the scarcity of medical resources in India, Xiaomi once again donated 30 million rupees, purchased more than 1,000 oxygen machines for hospitals in various states in India, and cooperated with local nonprofit organizations to raise 10 million rupees. These donation activities benefited the most severely affected areas, such as Delhi, Maharashtra, and Karnataka.

Still, Xiaomi was hit by a combination of weakened production capacity and stagnant sales amidst the growing pandemic in India as well as the geopolitical friction between China and India. In response, Xiaomi took a series of countermeasures, many of which took advantage of its reputation for ethical business practices. 
In September 2021, four applications from Xiaomi were included on the banned list by the Indian government-led boycott campaign against Chinese products. In this situation, Xiaomi responded by focusing the public attention on its local supply chain in highlighting "Xiaomi Made in India" in order to reinforce its local brand identity to mitigate consumer resistance. Eventually, Xiaomi managed to stay in the top second position for Q3 CY 2020 although losing the number one share in the Indian mobile phone market.

In summary, in the post-pandemic era, Xiaomi India should rely heavily on its reputational assets for ethical business practices and use its industry leadership position to learn positive lessons from other international multinational companies as well as local ones.

\section{Xiaomi lays out its distribution model in the post-pandemic era}

The distribution channels of Xiaomi India can be roughly divided into online and offline channels. In the post-pandemic era, Xiaomi should react quickly to maintain the online and offline layout to ensure the production and sales of its products in showing its corporate responsibility ${ }^{[3]}$. Meanwhile, Xiaomi should take a closer look on the pandemic dynamics and ensure its agility to be well-prepared for post-pandemic expansion.

\subsection{Xiaomi India's online distribution layout}

Due to the continuous worsening of the COVID-19 pandemic in May 2021, the Indian government restricted e-commerce services in most parts of India, allowing only essential goods distribution from all platforms in Delhi and Mumbai where electronic products are non-essentials. The ban reflects the fact that India's online sales channel has been greatly affected by the outbreak. Therefore, Xiaomi needs to make efforts to ensure a more stable online sales channel.

Xiaomi has its own mature online sale platform where users can browse the product catalog, product parameter details, questions and answers, and even provide customer feedback beside purchase.

How to ensure the smooth and fast delivery of goods is the big issue in the post-pandemic era. Gofer, an Indian e-grocery delivery platform, pointed out a common challenge that exists across multiple delivery platforms in India: Whenever new cases rise in a particular city, some couriers stop and write-off their services where they avoid the infection risk by returning to own hometowns.

The loss of couriers and its fluctuation throughout the pandemic have accelerated the instability of the delivery schedule which prevented consumers to receive their goods on time after payment, and damaged Xiaomi's brand image. At the same time, the risky or even insecure delivery of purchased goods would lead consumers to lose trust and patience towards online channels and eventually, choose to buy offline which is more direct but not conducive to the prevention and control of the pandemic. This is detrimental to the Indian society.

Xiaomi can cooperate with local e-commerce platforms and logistics companies while supporting the logistics network in two ways.

(1) Providing health and safety protection for courier delivery personnel. Xiaomi can set up a pandemic prevention and control fund for courier personnel to conduct nucleic acid testing, offer pandemic prevention materials needed for work, and purchase employee insurance. Xiaomi can also try its best to cooperate with the Indian government to allow couriers to be vaccinated on a priority basis.

(2) Establishing collection points. Xiaomi can partner with logistics companies and state governments to build access cabinets in areas with high courier flow and open official courier collection points. 


\subsection{Xiaomi India's offline distribution layout}

Offline stores are important sales channels for Xiaomi India. As of 2020, Xiaomi India has more than 4,000 large retail partners and 3,000 retail stores per study. Indians depend more on offline stores than most other regions in the world. Each region has their own respective offline purchase channels due to diverse economic conditions and development levels.

Overall, the Indian market can be divided into three levels for Xiaomi's reach following the Indian administrative divisions in conjunction with their local economy and infrastructure status, such as roads, electricity, network, etc. Xiaomi should establish various offline sales channels which are subjected to region or area consumption habits, local area gross domestic product (GDP), and living index in different markets.

(1) Tier 1 markets consist of major cities, such as the capital city of the first-level administrative region (New Delhi, Chennai, Bangalore, Kolkata, etc.). The first-tier market has a greater concentration of smartphone consumers as well as higher consumption levels. Xiaomi can open a range of offline sales channels in Tier 1 markets and flexibly adjust its sales programs according to the pandemic situation and site conditions.

(a) Mi Store, as Xiaomi's official directly managed store, aims to sell mobile phones and build brand stickiness.

(b) Retail outlets normally sell various brands of mobile phones through buy and sell.

(c) At bazaars, phones can be sold by Xiaomi employees or by non-Xiaomi employees. The former is like a Mi Store, and the latter is similar to retail outlets.

(2) Tier 2 markets include developed central urban areas where residents hold gatherings. These areas are not as developed as Tier 1 markets, but consumers are still concentrated and have a certain level of consumption. The sales channels and methods of selling in Tier 2 are similar to those in Tier 1 with varies framed in three perspectives: (a) the scale of sales in the secondary market is smaller; (b) Mi Stores are not opened; (c) the mobile store, named 'Mi Store on wheels' is introduced. Mi store on wheels is a minivan-based mobile store that will cover a specific route and stop at places where people in rural India hold weekly meetings or street fairs. This new omnichannel sales solution which combines display and sales can compensate for the lack of traffic in offline stores during the pandemic and effectively control the cost of opening a store.

(3) Tier 3 markets are mainly the central areas in developed villages and have the following characteristics: relatively blocked compared to Tier 1 and Tier 2 markets; remote and inaccessible. The total demand for mobile phones is large but the revenue per unit area is low due to overdistribution. The offline channel is the residents' only purchase channel. Xiaomi has basically no sales experience and foundation in this market. Based on the above characteristics, Xiaomi needs to develop new ways to reach consumers proactively while controlling promotion and transportation costs.

(a) Husband-and-wife store sales. The main business of the husband-and-wife store is to sell daily necessities, groceries, etc. These stores can be used as agents to sell Xiaomi mobile phones.

(b) Sales representative. Xiaomi can work with Grameen Bank ${ }^{[4]}$ to recruit and train local lowincome groups in the Tier 3 market to become sales representatives. The mode of the cooperation between Xiaomi and Grameen Bank could run in steps. Firstly, area managers of Grameen Bank should call for a center meeting across the villages where Xiaomi 
employees are invited to introduce how to use the Xiaomi smartphone. Then, every five members who are interested in Xiaomi's sales agent business is grouped to attend an in-depth training session to learn detailed product information as well as on how to use and sell mobile phones. After successfully passing the training session, some of the members would receive small loans from Grameen Bank and become Xiaomi sales agents. With this new role and mortgage loans, Xiaomi agents would receive smartphones, prototypes, introduction, and printed advertisements to start up their sales journey. Once they receive commission rewards for their sales performance, they can use them as a deposit to obtain more products for sales, thus running up toward a business growth. Finally, sales agents would then repay the loans to Grameen Bank during the weekly center meeting, develop business and life skills, as well as establish a close support network.

These sales agent plans can broaden and extend Xiaomi's sales channels and bring considerable income to the low-income local people. It is a win-win situation for Xiaomi and the local residents. However, problems might arise with the sales agent project. Smartphones cost more, depreciate faster, and are sold for higher prices compared to products generally sold by the residents. These factors may cause unaffordable inventory accumulations which can lead to business failure. Agents involved might eventually run into debt or even bankruptcy. In order to avoid these failures, Xiaomi should be fully transparent about business risk, proactively and openly share the risk of the project to the sales agent candidates during center meetings, as well as choose members that have business experiences and good credit records when the project is first launched.

Xiaomi should also extend the advanced digital system established in China to India for sales agents' usage, introduce the one-product-one-code technology to India, as well as request and train agents to scan products' special QR code with specific software after completing the sale. This procedure can secure anticounterfeiting and traceability of the goods, enhance the credibility of the agent, and provide customers with secure shopping experiences.

In order to share customer insight, Xiaomi should quickly collect series of data with customer consent, including sales volume of different representatives, market preferences, and consumer profiles subjected to various regions. These data could create customer profiling and insight which Xiaomi can directionally distribute goods after comprehensive scoring each agent, and offer recommendations to the respective agents in terms of suitable stock keeping unit (SKU), inventory volume, etc.

In this way, Xiaomi can mitigate the business risks of local sales agents, supplement their market insight, and equip them with right tools to build a healthy small business.

\section{Summary and outlook}

During the pre- and mid-pandemic outbreak, Xiaomi India, as an overseas company, should pay extra attention and comply to ethical business standards which give full consideration to the complexities of the pandemic and politics to which it will inevitably give rise to.

After the pandemic situation stabilizes, Xiaomi India can actively promote both the online and offline sales channels as well as introduce the one-product-one-code technology to stabilize and expand Xiaomi India's distribution system. At the same time, Xiaomi India can bring unique value to the Indian retail market by promoting e-commerce.

\section{Disclosure statement}

The author declares that there is no conflict of interest. 


\section{References}

[1] Ling H, 2018, Research on the Entry Strategy of Chinese Mobile Phone Companies in the Indian Market. Zhejiang University.

[2] Mahdavi G, Daryaei AA, 2017, Attitude toward Business Environment of Auditing, Corporate Governance and Balance between Auditing and Marketing. Contaduría y Administración, 62(3): 101940 .

[3] Shih CC, Lin TMY, Pin L, 2014, Fan-Centric Social Media: The Xiaomi Phenomenon in China. Business Horizons, 57(3): 349-58.

[4] Nisha N, Iqbal M, Rifat A, 2020, A Comparative Integration Study of Performance Metrics in Microfinance: Grameen Bank vs. Cooperative Bank. International Journal of Information Systems in the Service Sector, 12(3): 55-73. 